\title{
Towards an Open Access European Database for Deep Seismic Sounding Data
}

Carbonell, R., DeFelipe, I., Alcalde, J., Ivandic, M., Roberts, R.

Contact: Irene DeFelipe, idefelipe@ictja.csic.es

ICTJA

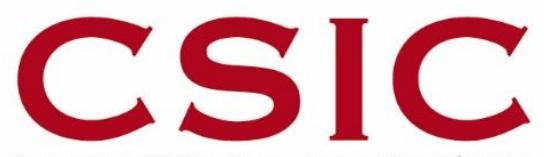

CONSEJO SUPERIOR DE INVESTIGACIONES CIENTIFICAS

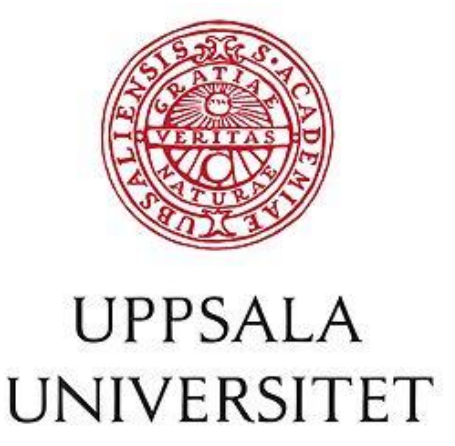

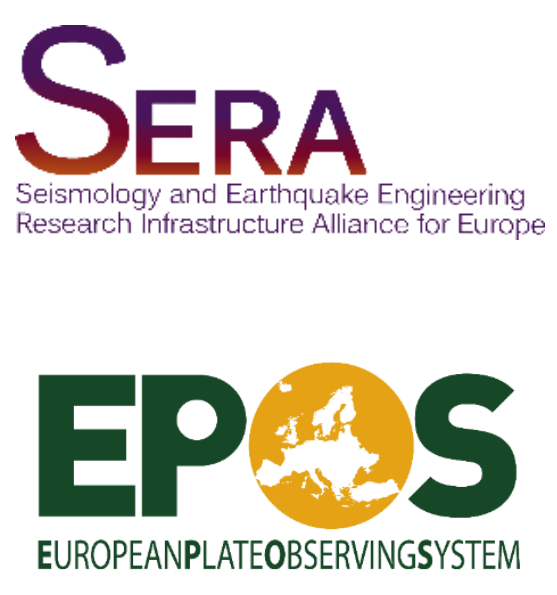




\section{DSS project database}

- Data represents a solid base to move science towards wisdom and novelty.

- Deep Seismic Sounding (DSS) data provides critical information of the crust and lithosphere, is the base of Solid Earth Sciences and results from a huge scientific effort among different institutions. Thus, DSS data needs to be preserved.

- To develop a prototype for DSS data access, seismic datasets are assigned a DOI, following the FAIR principles of data management: Findable, Accessible, Interoperable and Reusable. 


\section{DSS project database}

- EPOS (European Plate Observation System) and SERA (Seismology and Earthquake Engineering Research Infrastructure Alliance for Europe) are international projects that offer data access in Solid Earth Sciences and specifically, in seismology. To create a "project database" within the EPOS metadata system, we have:

- Collated a list of DSS projects (ECORS, ESCI, DEKORP, TRANSALP, HIRE, URSEIS, EUROBRIDGE, EUGENO, etc.) and metadata in existing databases (OpenFIRE, CSIC and BIRPS).

- Contributed to inform the DSS community on the SERA objectives and included the community in the discussions.

- Communicated with international specialists on control source seismic exploration.

These discussions have significantly contributed to our roadmap. However, engagement of the DSS community will be still needed to proceed in the future.

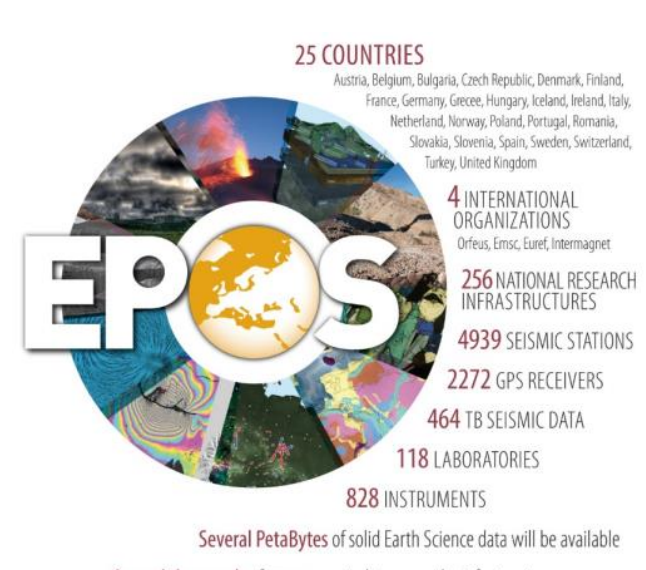

Several thousands of users expected to access the inffastructure

https://www.epos-ip.org/

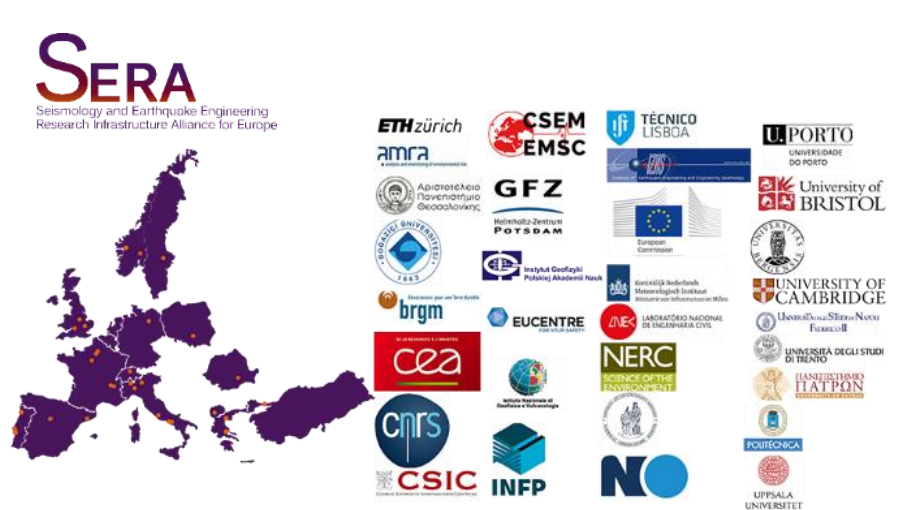

http://www.sera-eu.org/en/home/ 


\section{Prototype: ICTJA-CSIC seismic database}

- Digital.CSIC hosts an online repository where scientific data and data products are freely available.

- The Institute of Earth Sciences Jaume Almera (ICTJA) and digital.CSIC have encouraged a database of DSS data. CSIC aims to treat current dataset as published papers through DOI and handle.

- The ICTJA-CSIC seismic database includes normalincidence and wide-angle DSS data acquired both onshore and offshore. They sample different geological settings at different scales.

- Seismic data are available in:

https://digital.csic.es/handle/10261/101879

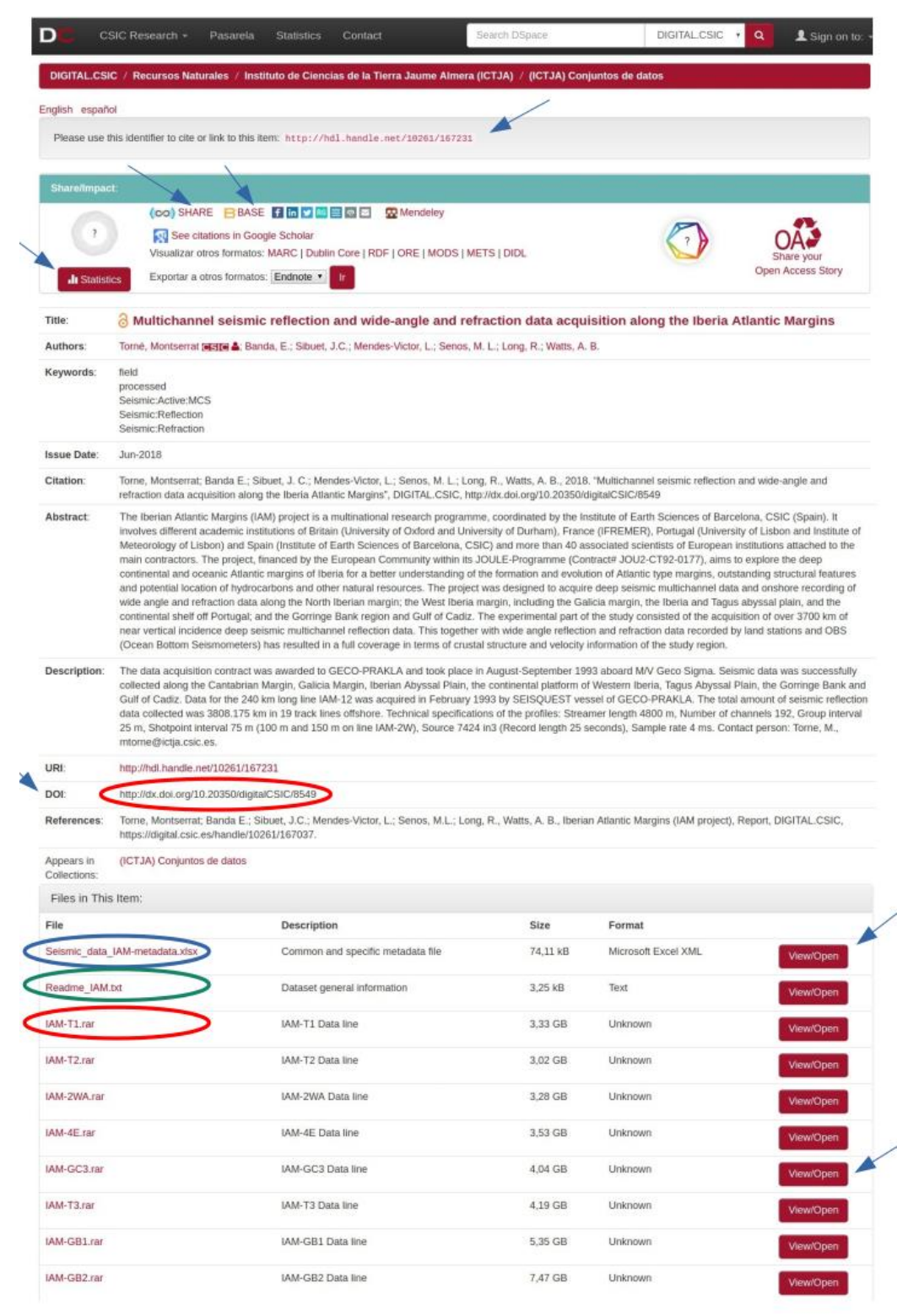




\section{Prototype: ICTJA-CSIC seismic database}

- Total downloads by region:

continente

USC - USA \& Canada

EUR - Europa

CH- China

Отн - Otros \& no defrnidos

LA- Latinoamérica

ASIA - Asia, otros

JPN - Jpn, S.Kor \& Taiwan

Aus - Aus \& NZ

HK - Hong Kong

AFR - África
- Total downloads by time:

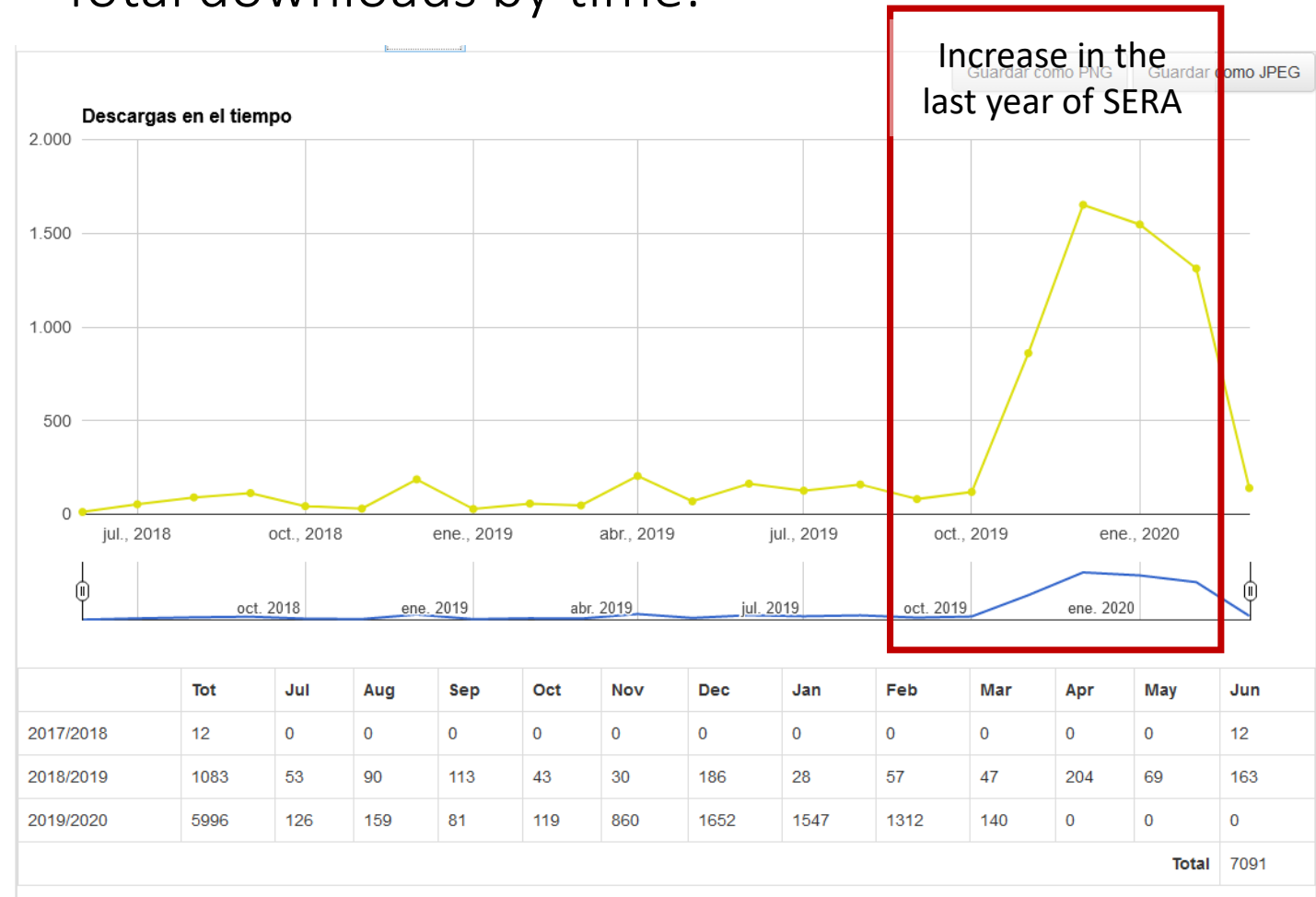




\section{Future perspective of DSS data}

- A continued collaboration of the DSS community is needed to move towards an open access DSS database.

- Digital.CSIC provides a great advance into the dissemination of the research data and results following the FAIR principles and is able to generate DOIs for different formats of datasets. It provides the infrastructure to accomplished the open access legal requirements.

- An open access database aims to facilitate knowledge discovery, to improve research transparency and to spread science for research, education and industry. 